\title{
Should I stay or should I go? An experimental study on voter responses to pre-electoral coalitions
}

\author{
THOMAS GSCHWEND ${ }^{1} \&$ MARC HOOGHE $^{2}$ \\ ${ }^{1}$ University of Mannheim, Germany; ${ }^{2}$ Catholic University of Leuven, Belgium
}

\begin{abstract}
Pre-electoral coalitions (PECs) are one of the most often used methods to coordinate entry into the electoral market. Party elites, however, do not know how voters will respond to the coalition formation at the polls. In this article, the authors report on an experimental study among 1,255 Belgian students. In order to study voter responses to the formation of PECs, respondents were presented with two ballots: one with individual parties (party vote condition) and one with coalitions (coalition vote condition). The aim of this experiment is to predict under what conditions party supporters will follow their initially preferred party into the coalition and vote for the PEC, and under what conditions they would desert the PEC at the polls. The decision whether to follow the coalition or not can be traced back to four considerations: dislike of the coalition partner; ideological congruence between coalition partners; size of the initially preferred party; and being attracted to a specific high-profile candidate. (Dis)liking the coalition partner is independent from the ideological congruence between the two coalition partners. The study's results also show support for an adjustment effect, as respondents became more loyal toward cartels over the course of the 2003-2005 observation period.
\end{abstract}

\section{Introduction}

It can be assumed that political actors, in one way or another, coordinate their entry into the electoral market depending on a number of institutional and legal constraints. In majoritarian electoral systems, small political parties are discouraged from participating in elections since they are unlikely to obtain any seats and, as a result, the votes they do assemble simply will be wasted (Cox 1997; Ferrara \& Herron 2005). One of the basic, and most-often used, mechanisms to coordinate entry into the electoral market is the formation of pre-electoral coalitions between parties (Golder 2005, 2006). Political parties can choose to compete with a joint manifesto, support common candidates or strategically withdraw in favour of their coalition partner, announce that they want to form a governing coalition after the elections, and field their candidates on a common election list (Powell 2000). In some electoral systems, this form of strategic coordination is endemic: in the run-off to the second round 
of the French elections, parties have to decide whether or not to call on their supporters to vote for one of the remaining contenders (Gschwend \& Leuffen 2005).

An obvious advantage of pre-electoral coalitions is that they allow the partners to profit from the economy of scale that is inherent even in fairly proportional electoral systems. In general, all electoral systems disadvantage small parties and favour large parties when it comes to the translation of votes into seats. In disproportional electoral systems, however, the gains of a preelectoral coalition can be quite considerable and comparative research indeed shows that this from of strategic coordination is most frequent in countries with a strongly disproportional electoral system (Golder 2005). Golder also demonstrates that pre-electoral coalitions can hardly be called a marginal phenomenon. In the 22 advanced industrial democracies she studied for the 1946-1998 period, there were 134 general elections in which at least some of these pre-electoral coalitions presented themselves to the voters.

We do not know, however, whether the formation of pre-electoral coalitions (PECs) can actually be seen as a successful coordination formula. On the one hand, the electoral system can offer clear incentives for joining forces, but, on the other hand, politicians are confronted with one very important source of uncertainty: they do not know how voters will respond to the coalition. Even if the party elite, on strategic grounds, decides that such a coalition is a promising option, it might still be the case that voters do not feel that their views are sufficiently represented in the new coalition. For party elites, therefore, the problem is that they must decide and react to incentives inherent in the electoral system, while at the same time they are confronted with great uncertainty about the likely behaviour of the voters (Andrews \& Jackman 2005; Boix 1999).

At present, there is no research available on the question of how voters respond to the formation of PECs. Under what conditions are party supporters likely to follow their initially preferred party into the coalition and vote for the PEC and under what conditions would they desert the PEC at the polls? The main impediment to answering this question is that we do not have a reliable way to ascertain what would have been the electoral fate of the coalition partners if they had not joined the coalition. For example, in the 1986 general elections in the Netherlands, four small leftist parties jointly obtained 3.3 per cent of the vote, resulting in three seats in the Second Chamber. In 1989, these four parties merged into a 'Green Left' coalition that obtained 4.1 per cent of the vote resulting in six seats. At first sight this seems like a minor success, but there is no way to ascertain the impact of the formation of the coalition itself. Maybe these green and leftist parties would have gained votes anyway. Since in most electoral systems voters only have one opportunity to express their vote, no further information is available. In real-life conditions, the question of 
whether or not a coalition was successful thus can only be a counterfactual one. If we want to find out whether voters are indeed likely to follow their party into a coalition, it is clear we will have to rely on survey or experimental data. In the experiment we report in this article, we try to ascertain under what conditions voters are more or less likely to follow their initially preferred party into a PEC.

\section{Data and methods}

We employ an experimental design to study the reaction of voters to the formation of pre-electoral coalitions. In this experiment (a within-subject design), we presented voters with two different electoral ballots: one with all the political parties in Belgium included (party vote condition), and a second with only the pre-electoral coalitions as they actually appeared on the ballots in the 2004 regional elections in Belgium (coalition vote condition).

Belgium offers a particularly good context to study the way voters respond to these coalitions because in 2003 the country adopted an electoral threshold of 5 per cent of the vote at the primary district level. As a reaction to this new electoral law, three coalitions quickly emerged. The Christian-Democrats $(C D \& V)$ joined forces with the Flemish Nationalists of N-VA; the Socialists (SP.A) concluded a coalition with the progressive nationalists of Spirit; and the Liberals (VLD) introduced a common list with the small anti-tax party Vivant (Hooghe et al. 2006a). For the smaller parties (N-VA, Spirit and Vivant), the coalition offered an opportunity to escape the threat of the new threshold, while the larger parties (CD\&V, SP.A and VLD) hoped that the extra votes would give them a competitive advantage in their ongoing struggle to become the largest party in Flanders, the largest autonomous region in Belgium. Since the creation of the autonomous region, the general rule is that the largest party in the region can claim the post of prime minister of the Flemish government, so there is a clear premium in emerging as the largest party in the elections. The contest is open, since Christian-Democrats, Socialists and Liberals all score somewhere between 19 and 23 per cent of the vote.

To conduct this kind of experiment, it is of crucial importance that respondents have to make two independent voting decisions: one on a ballot without coalitions, and one on a ballot with coalitions. Standard survey techniques do not offer a good method for this experiment: even when employing professional interviewers, there is still a risk that the respondent will refer back to his or her initial vote, before giving an answer to the second vote. One can assume that respondents want to present their choices as logically coherent, so if there is a way to retrieve their first vote, it is likely that they will cast their second 
vote in a consistent manner, and thus they will follow their initially preferred party into the coalition. To avoid this kind of contamination, we opted for an experiment with a web-based survey design. Using a within-subject design, respondents were confronted with separate screens for every question, with sufficient questions between the first (party vote condition) and the second ballot (coalition vote condition). When confronted with the second ballot, there was no way the respondents could get back to the vote they had cast on the first ballot, so we assume we get a more reliably 'sincere' answer.

All three PECs were based on the same model: the participating parties clearly kept their overall autonomy, but they presented their candidates on a joint list (labelled, e.g., 'SP.A-Spirit'). The parties also agreed on a joint electoral platform and announced plans to enter coalition talks together.

The experiment was conducted with first-year university students in Belgium, shortly after the introduction of the coalitions. A total of 1,255 students participated, in three consecutive academic years from 2003 to 2005 (Hooghe et al. 2006b). The various waves of this experiment allow us to study more closely the dynamics of the entire process of PEC acceptance across time. Every student enrolled in an introductory course on political science received an email with the request to participate in the study. Only about a quarter of all these students actually were pursuing a degree in political science, since most of them were enrolled in other programmes (communication science, law, sociology, philosophy, area studies, etc.). The email also contained a unique access code that could only be used once. All questions had to be answered in a correct manner before the survey was labelled 'completed'. Students whose access code had not been used received a reminder after a week. In the end, more then 90 per cent of all first-year students participated in the experiment. Self-evidently, students were not taught about electoral behaviour before the experiment was conducted, and received all necessary information about this experiment after they had participated in it. Since this study is based on an experiment with a very specific student sample, it should be clear that the figures reported in the remainder of this article are not meant to be representative as the experiment was only conceived to demonstrate the causal processes that occur among voters in response to the formation of pre-electoral coalitions at the polls. ${ }^{1}$

\section{Hypotheses}

When trying to model voters' responses to the formation of a coalition, it has to be kept in mind that voters have two options. They ask themselves whether 'to stay' or whether 'to go'. On the one hand, voters could follow the party 
elites of their preferred party and, if the elites decide to form a pre-electoral coalition, subsequently they stay within the coalition. This implies that they vote for the PEC since the individual parties (SP.A, VLD, etc.) are no longer represented separately on the ballot paper. On the other hand, voters could refuse to follow their preferred party and desert the pre-electoral coalition to which their party belongs and cast their vote for some other party or coalition. ${ }^{2}$

There are two different reasons to expect that many voters will follow the lead of their party elites. First, if we assume that voters are instrumentally motivated and looking for ways to optimise the effect of their vote, it seems likely that they will follow the party elite of their initially preferred party. These voters will indeed understand the considerable benefits of joining a preelectoral coalition so they will understand that their votes will not be wasted if they join the coalition. If voters follow a seat-maximising logic, as Cox (1997: 272) argues, given their party preferences, they have every reason to vote for the coalition. Second, following low information rationality models in political science (e.g., Downs 1957; Lavine \& Gschwend 2007; Popkin 1991), voters as 'cognitive misers' (Fiske \& Taylor 1991) rely on heuristic shortcuts instead of calculating complicated issue distances so that they can form meaningful appraisals of parties without expending much cognitive effort. Based on this literature one could speculate that it requires too much effort to evaluate the new choice-set options, consisting of formed party coalitions, independently from the cues provided by the elites of their preferred party. Thus, again, they are predicted 'to stay' rather than 'to go' and to follow their party into voting for the relevant PEC.

Under what conditions might voters deviate from these baseline predictions and not respond to the formation of PECs as the negotiating party elites suggest? Thus far this question, which is of course crucial to determining the success and the impact of PECs, has never been studied, so we cannot build on earlier research. Nevertheless, the general literature on voter choice allows us to develop five basic hypotheses based on ideological similarity, party size, evaluation of the coalition partner, preference for specific candidates and the time elapsed since the coalition was established.

Golder (2006) shows that the successful formation of a PEC is largely dependent upon the ideological distance between the coalition partners. We expect that a similar logic is electorally relevant, as well. Voters are not likely to cast their votes for the sponsored coalition of the party they otherwise support if they expect that there will be too many policy concessions to make. The more congruent the ideological positions of the coalition partners, the smaller the ideological distance and the more likely it is that supporters of the constituent parties will support the PEC at the polls. If the ideological distance is too large (i.e., ideological congruence is too low), it becomes more attractive 
to opt out of the PEC in order to vote for a third party that is perceived to be more similar to the programme of the initially preferred party (Ideology Hypothesis).

The size of the coalition partners is a crucial element in determining the outcome of coalition bargaining since it can be assumed that the senior coalition partners to a large extent will be able to impose their views on the junior coalition partners (Martin \& Vanberg 2003). Most of the time, junior coalition partners will have a hard time getting their views incorporated into the joint platform and, for supporters of these small partners, there are therefore fewer reasons to feel represented by the manifesto of the cartel. All three coalitions in Belgium involved a large (CD\&V, SP.A and VLD) and a small party (Vivant, Spirit and N-VA), and the basic expectation is that the larger partner will have the strongest impact on the common platform for the elections. All things being equal, we can assume that small party supporters will find less of their ideological preference reflected in the common platform than supporters of the senior coalition partner. Therefore, small party supporters should be more likely to desert their party's coalition because they might feel that the cost for not 'going for it alone' is too high to justify making many cooperative agreements with the coalition partner that in the end might threaten the identity of the small party. Although small party supporters might have stronger instrumental incentives to consider the cartel as a survival mechanism for their party, we assume that the ideological considerations will be more influential in determining their voting decision. Our second hypothesis therefore is that supporters of smaller coalition partners more easily defect from the party strategy than voters for the major coalition party (Asymmetry Hypothesis).

The Asymmetry Hypothesis assumes that supporters of small parties are less likely to vote for the cartel because they find less of their ideological preference reflected in the common platform. If one assumes, however, that the decision to join the cartel is made in an instrumental manner, this assumption does not make any sense. Basically our hypothesis predicts that ideological distance will matter more for small party voters than for voters of the major coalition partner. To test this assumption more directly, in some of our models we will also include an interaction effect between the Ideology and the Asymmetry Hypotheses.

Particularly following low information rationality models, voters could heavily rely on likeability heuristics regarding parties or candidates in order to make their decisions (Fiske \& Taylor 1991). Even independently from hard-to-process information like policy distances between the preferred party and the coalition partner, party supporters will vary in how much they like or dislike their party's coalition partner in the PEC. This preference is not necessarily related to ideological congruence-for instance, while an N-VA voter 
might be ideologically close to the Christian-Democrats of CD\&V, he or she might still dislike the $\mathrm{CD} \& \mathrm{~V}$ because of the historically dominant position of that party, which has caused some critics to accuse this party of an arrogant attitude toward political power. In the same vein, SP.A voters might still dislike Spirit, not so much because of the current programme of that party, but rather because of the historical role of Flemish nationalism. Voters therefore might be cross-pressured because they prefer a party, but dislike its coalition partner. Thus we expect party supporters to be all the more motivated to desert the coalition the more they dislike the coalition partner (Coalition Likeability Hypothesis).

Voters, however, are not just concerned about parties and programmes, but also about candidates. Wattenberg (1991), for example, assumes that voters' evaluations of the personalities of candidates play an increasingly important role in determining electoral preferences. To test the importance of candidatecentred politics, we also include a question on the candidate the respondent most liked. Our hypothesis is that if the most-liked candidate does not belong to the coalition, respondents face serious cross-pressures that make them more likely to opt out in order to vote for that preferred candidate from a completely different party. If, however, the most-liked candidate belongs to the initially preferred party or its coalition partner, this might serve as an incentive to remain loyal to the coalition (Candidate Likeability Hypothesis).

It can be argued that time also plays a role in determining voters' responses. The formation of a PEC implies that voters, to some extent, are required to re-adjust their mental map of the political space according to clues provided by the party elites (Kabashima \& Reed 2000). A party that was presented as being the 'enemy' just a few months earlier might become a strategic partner in the next elections. Voters need time to adjust to such coalition signals because they need to learn how to respond to changes in the electoral environment. We therefore expect that the likelihood of voters following their party into a coalition should be dependent on the time elapsed since the establishment of the PEC. We expect that the more time they have had to adjust to the new coalition signals sent out by party elites, the more likely they will be to follow their party elite into the cartel (Adjustment Hypothesis).

After providing some context about the Belgian case in the following section, these five hypotheses will lead us through the analysis of our results.

\section{The Belgian case}

Belgium offers an excellent case for the study of the electoral success of PECs since these coalitions were a new phenomenon in 2003-2004. Partly because of 
the linguistic divide in the country, Belgium has one of the most fragmented party systems in Europe. ${ }^{3}$ This fragmentation became even stronger when the moderate Flemish-nationalist party Volksunie split in 2000. It was feared that this process would make it even harder in the future to form stable and reliable coalition governments. Even now, Belgian governments are composed of five or six parties.

One of the reforms the government proposed in 2002 to halt the further fragmentation of the party system was the introduction of a 5 per cent threshold. This measure was directed specifically against the two successor parties of the Volksunie: the moderate Spirit and the more radical-nationalist New Flemish Alliance (N-VA). Already before the federal elections of 2003, Spirit joined forces with the Socialist Party, while the N-VA went to the polls on its own, obtaining 4.8 per cent of the vote. Because of the application of the electoral threshold at the district level, this resulted in just one seat in the Chamber. As a result of this negative experience, shortly thereafter N-VA joined forces with the Christian-Democrats of CD\&V.This meant that only the Liberal Party (i.e., the governing party of Prime Minister Guy Verhofstadt) was left without a coalition partner. In the end, the VLD joined forces with a small anti-tax party, Vivant, which was not represented in parliament (Hooghe et al. 2003). The Greens and the extreme-right Vlaams Blok were the only two parties not involved in the process of forming coalitions. The Greens insisted on keeping their autonomy, despite clear and persistent invitations from the Socialist Party, while nobody wanted to cooperate with the Vlaams Blok.

When looking at the results for the 2003 federal and the 2004 regional elections (Table 1), the SP.A/Spirit coalition at first sight looked quite successful. In fact, the electoral success of this PEC served as a powerful incentive for the formation of the other two PECs in the months following the 2003 elections. In 2004, however, the VLD suffered a clear defeat, despite its alliance with Vivant, and the SP.A/Spirit coalition also lost votes. CD\&V and N-VA hardly gained any new voters, but they clearly emerged as the largest party in Flanders. Subsequently, CD\&V chairman Yves Leterme became prime minister of the new Flemish government.

\section{Experimental design, operationalisation and results}

In order to understand how voters responded to the formation of PECs in the real world we conducted a vote-choice experiment using the same coalition and familiar party name labels. We are interested to explain whether there are systematic determinants that help predict under what circumstances voters are 
Table 1. Election results, 1999-2004

\begin{tabular}{lccc}
\hline & 1999 & 2003 & 2004 \\
\hline VLD & 21.7 & 24.2 & 19.8 \\
Vivant & 2.0 & 1.2 & \\
Volksunie & 9.1 & split into N-VA & and Spirit \\
SP.A & 14.8 & 23.5 & 19.7 \\
Spirit & - & & \\
CD\&V & 22.1 & 21.0 & 26.1 \\
N-VA & - & 4.8 & 7.6 \\
Agalev/Groen! & 11.5 & 3.9 & 24.2 \\
Vlaams Blok & 15.8 & 17.9 & \\
\hline
\end{tabular}

Note: Results in percentages for: 1999 Flemish parliamentary elections; 2003 Chamber of Deputies elections in Flemish districts; 2004 Flemish parliamentary elections.

Source: Ministry of the Interior.

likely to defect from the pre-electoral coalition strategies of their party elites. Therefore we designed a within-subject experiment whereby every respondent is assigned to two conditions.

In the party vote condition, respondents report their vote intention when the only options on the ballot are single parties. In the coalition vote condition, the choice-set changes slightly. In this condition, the parties forming one of the three PECs are only presented under the heading of their coalition, together with the other parties that ran independently. All respondents, again, report their vote intention for one of these options given the changed choice-set. ${ }^{4}$ In order to detect any ballot order effects, in 2005 the order of the various conditions was randomly assigned (first party vote and then coalition vote condition, or the other way around). The analysis showed, however, that the order of the conditions had no effect whatsoever on the results. We are primarily interested in those respondents who desert 'their' party (i.e., the party they support in the party vote condition) when it is only presented as a member of a pre-electoral coalition in the coalition vote condition. ${ }^{5}$

The figures in Table 2 represent the results of these mock-elections. The rows represent the voting behaviour in the party vote condition. When confronted with nine separate parties on the ballot, 334 students voted for the Socialists (26.6 per cent), 258 for the Christian-Democrats ( 21.2 per cent), 224 for the Liberals (16.9 per cent) and 200 for the Greens (13.5 per cent) ${ }^{6}$ The columns in Table 2 represent the voting behaviour in the coalition vote condition when the respondents received a ballot with the PECs on it. Here, SP.A/Spirit became the largest coalition, with 418 'votes', or 33.3 per cent of the vote. 
Table 2. Results of party vote and coalition vote conditions (2003-2005 joint sample)

\begin{tabular}{lrrrrrrr}
\hline & \multicolumn{7}{c}{ Coalition vote condition } \\
\cline { 2 - 7 } $\begin{array}{l}\text { Party vote } \\
\text { condition }\end{array}$ & $\begin{array}{c}\text { VLD/ } \\
\text { Vivant }\end{array}$ & $\begin{array}{c}\text { SP.A/ } \\
\text { Spirit }\end{array}$ & $\begin{array}{c}\text { CD\&V/ } \\
\text { N-VA }\end{array}$ & Groen! & $\begin{array}{c}\text { Vlaams } \\
\text { Blok }\end{array}$ & Others & N \\
\hline VLD & 195 & 12 & 9 & 4 & 2 & 3 & 225 \\
Vivant & 8 & 5 & 1 & 1 & 0 & 5 & 20 \\
SPA & 3 & 308 & 9 & 11 & 1 & 2 & 334 \\
Spirit & 3 & 52 & 4 & 0 & 0 & 0 & 59 \\
CD\&V & 4 & 21 & 227 & 6 & 0 & 0 & 258 \\
N-VA & 12 & 2 & 71 & 2 & 2 & 2 & 91 \\
Groen! & 3 & 13 & 5 & 178 & 0 & 1 & 200 \\
Vlaams Blok & 1 & 3 & 6 & 0 & 35 & 0 & 45 \\
Others & 3 & 2 & 0 & 1 & 0 & 17 & 23 \\
N & 232 & 418 & 332 & 203 & 40 & 30 & 1,255 \\
Percentage & 18.5 & 33.3 & 26.5 & 16.2 & 3.2 & 2.4 & 100.0 \\
Flanders, & 27.1 & 27.7 & 22.6 & 6.5 & 16.1 & - & 100.0 \\
$\quad$ population & & & & & & & \\
14-29 years & & & & & & & \\
\hline
\end{tabular}

Notes: Results of the experiments; entries are number of respondents voting for that party, respectively, in the party vote condition (rows) and the coalition vote condition (columns). Final rows: percentage among this sample, and percentage among 14-29 year-old respondents in European Social Survey 2004 for Flanders.

In the bottom line of Table 2 we also offer a quick comparison between participants in this experiments and young Flemish respondents (14-29 yearolds) in the European Social Survey (2004). The comparison shows that Christian-Democrats and Socialists are fairly well represented in our sample, and the extreme-right party Vlaams Blok scores much better in the population sample, while the Greens are over-represented in the experiment. In general, participants in this experiment show the electoral preferences one would expect in a young student sample. Furthermore, the largest differences can be observed for the Greens and the Vlaams Blok - two parties that did not enter a PEC and therefore do not play a role in our analysis.

When we combine the results from the party vote condition with the results from the coalition vote condition, it is clear that the vast majority of the respondents voted in a consistent manner. Of 224 initial VLD voters, 195 followed the cues from the party elite and voted for the VLD/Vivant coalition. This means, however, that 29 respondents deserted the coalition, and distributed their votes among all the other parties. While the VLD/Vivant coalition 
received 203 votes from VLD and Vivant, the coalition succeeded in attracting another 29 respondents who had not voted for VLD or Vivant under the party vote condition.

The results show that 861 respondents followed their initially preferred party into the coalition, but another 123 respondents did not. These respondents allow us to determine why some voters do not follow the party elite into a pre-electoral coalition. One could still argue that these deviations are simply the result of a random answering pattern as respondents in condition B clearly no longer know what they have voted for in condition A. In the remainder of this article, however, we will ascertain whether these deviations are simply random, or whether they follow a well-structured pattern. The 271 remaining respondents (Greens, Vlaams Blok or 'Others' under the party vote condition) are not included in the analysis. While it might be interesting to find out why some of them abandoned their original party preference to join a coalition, the numbers are too small to make a meaningful analysis.

Simply looking at Table 2 provides the first evidence for the asymmetry we argued is inherent in voters' decision making about whether or not to stay with the PEC. Relative to the loyalists who actually follow the lead of their party elites and cast their vote for the pre-electoral coalition to which the party belongs, supporters of the small coalition partners (Vivant, Spirit and N-VA) seem to desert more often than supporters of the larger coalition partners (CD\&V, SP.A and VLD). ${ }^{7}$ While the junior coalition partners initially attracted 170 voters, 131 of them remain loyal to the cartel (77 per cent). The senior coalition partners, on the other hand, attracted 816 voters, of which 730 ( 89 per cent) remained loyal to the subsequent cartel.

In the following analysis, our dependent variable is 'Coalition Desertion', coded ' 0 ' for voters who followed their initial party into the coalition and ' 1 ' for voters that initially voted for one of the coalition partners, but subsequently deserted the coalition in the coalition vote condition. We also constructed several independent variables to test our hypotheses conjointly. In order to test our Ideology Hypothesis, we needed a comprehensive measure of policy distances or policy congruence. This proved to be quite difficult since of course we needed comparable data for all three PECs. It was especially difficult to get an estimate for the VLD/Vivant coalition ${ }^{8}$ since, because of its small size, Vivant is not always included in election surveys. Finally, we decided to use a double measurement for policy congruence: one resulting from the party presidents themselves and one relying on an estimate from our own respondents.

During the campaign for the 2004 regional elections, the Flemish public broadcasting network (VRT) ran a number of shows in which viewers could ascertain to what extent their own policy opinions corresponded with the policy options in the party programmes. To make this comparison possible, the 
VRT asked two well-known academics to compile a list of 84 policy proposals, and this list was presented to the chairpersons of all parties in Flanders so that they could indicate the position of their party on each one of these issues. Since this show, Doe de Stemtest, attracted some 800,000 viewers, or almost a quarter of all Flemish voters, all party presidents were more than willing to accede to this request.

The 84 policy proposals were chosen to reflect current political debates in the country, like: 'We don't need any new highways'; 'We should give more power to Europe'; and 'Those who receive unemployment benefits should be forced to accept any job'. If we analyse the answers to all questions, we can compute the correlation (pairwise) between all parties that participated in this event. The results show that the congruence between SP.A and Spirit (correlation of 0.74 ) is stronger than that between CD\&V and N-VA (correlation of 0.66 ) or VLD and Vivant (also a correlation of 0.66) (Deschouwer \& Nuytemans 2005: 21). Assuming that those policy congruence correlations did not change between 2003 and 2005, we get a first measure to assess the ideological congruence of all coalition parties during this period.

Our second measure relied on mean ideological placement scores when we asked respondents in 2005 to place each of the parties on a 10-point ideological left-right scale. The students also place SP.A and Spirit closer together than they did VLD and Vivant, or CD\&V and N-VA. We rescaled the mean ideological placement scores to range from 0 to 1 . Assuming that those mean distances between the coalition partners did not change from 2003 and 2004, we imputed these values for those years to get a second measure of ideological congruence of all coalition parties during this period.

The two measures are strongly correlated $(-0.80)$; negatively because small mean distances with the second measure correspond to high correlations between the coalition parties with the first measure. This strong correlation by itself might be interpreted as confirmation of the validity of both measures: apparently party presidents and first-year students agree very strongly on the ideological congruence of political parties. Rather than using any single imperfect ideology measure, we decided to combine the two measures into one ideological congruence score by subtracting the second measure from the first, averaging them and then rescaling those averages to range from 0 to $1 .{ }^{9}$

Our expectation is that voters, on average, have a more or less accurate idea about the ideological differences between two parties and thus their ideological congruence will play a major role in the voters' decision to vote or not to vote for a coalition. Our hypothesis is that the smaller the ideological congruence between two coalition partners, the more likely supporters of those coalition partners will be to desert the PEC. We expect therefore a negative 'Ideology' coefficient. 
The Asymmetry Hypothesis predicts that small party supporters should be a priori more likely to desert the PECs. Indeed, as Table 2 shows, supporters of the junior coalition partner are in general less loyal than supporters of the senior coalition partner. In our effort to operationalise 'party size', we encountered the problem that Spirit never participated on its own in elections, so unlike for the other parties, we do not have an objective way to determine the electoral strength of Spirit. Therefore we had to rely on a simple dichotomy between small and large political parties. We operationalise small party supporters as a dummy scoring ' 1 ' if they voted for one of the small coalition partners (Vivant, Spirit and N-VA) in the party vote condition and zero otherwise. We expect therefore a positive 'Small Party' coefficient.

According to our third hypothesis, the Coalition Likeability Hypothesis, we expect party supporters to be all the more motivated to desert a coalition the more they dislike the coalition partner. Respondents were invited to rank all the parties by asking them to rank their most disliked party, their second most disliked party and so on, until their most liked party would appear in the final position. The motivation to desert should be highest for supporters of one of the six coalition parties (CD\&V, SP.A, VLD, Vivant, Spirit and N-VA) if they strongly dislike their party's coalition partner. Therefore we constructed a scale ranging from ' 0 ' if coalition party supporters most like their party's coalition partner (after rescaling) to ' 1 ' if coalition party supporters most dislike the corresponding PEC partner. For example, an N-VA voter who ranks $\mathrm{CD} \& \mathrm{~V}$ as the most disliked party obtains a score of ' 1 '; if $\mathrm{CD} \& \mathrm{~V}$ would have been the most liked party, this voter would have been assigned a score of ' 0 '. Values between the endpoints ' 0 ' and ' 1 ' are assigned depending on which position a coalition party supporter ranks the corresponding coalition partner. Support for this hypothesis is indicated by a positive 'Coalition' coefficient.

In order to test our Candidate Likeability Hypothesis and control for candidate effects on respondents' propensity to desert a coalition, respondents were asked to choose their favourite candidate from a list of candidates. ${ }^{10} \mathrm{We}$ created a dummy scoring ' 1 ' if the respondent's most preferred candidate is neither affiliated with the party the respondent supports in the party vote condition nor affiliated with the coalition partner if the respondent supports one of the coalition parties. For those supporters, candidate appraisals are likely to cross pressure their party preferences. Thus, we expect the 'Candidate' coefficient to be positive: a voter that most prefers a candidate outside the coalition is more likely to opt out of the coalition.

Finally, the Adjustment Hypothesis can be tested because students took part in the experiment in three consecutive years: 2003, 2004 and 2005. ${ }^{11}$ In order to capture the data for this hypothesis, we construct a variable that measures the amount of time (in years) since the formation of the coalition. 
We expect, holding all other variables in the model constant, that supporters of cartel parties are becoming less likely to desert over time. Thus, the 'Time' coefficient is expected to be negative.

Since the dependent variable is dichotomous, we present a series of four logit models after pooling the data in order to test our hypotheses simultaneously. Table 3 summarises our estimation results. The models presented are based on a number of different assumptions. In our first model, we start in a rather straightforward manner by testing only our four static hypotheses. The analysis shows that disliking the coalition partner strongly encourages voters to desert the PEC, while the candidate and the small party effect are confirmed as well. Somewhat surprisingly, although the ideology effect is significant, the estimate is less precise than the other substantively interesting coefficients in the model. In our second model, we additionally allow for the possibility that the effect of ideology could be dependent on the size of the initially preferred party by including an interaction effect between small party and ideology congruence. This interaction effect, however, is not significant, indicating that supporters of small parties do not respond differently than supporters of the major parties to (the lack of) ideological congruence.

A unique feature of this experiment is that the data collection started in 2003, just after the PECs were formed in Belgium, and continued until 2005. This allows us to test the voter reactions to those coalitions over time. In model 3 we included the dynamic time variable to assess the evolution between 2003 and 2005. The effect is strongly negative, indicating that the odds that voters

Table 3. Voter responses to pre-electoral coalitions: Predicting PEC desertion, 2003-2005

Static with

Static interaction
(3)

Dynamic
(4)

Dynamic with interaction

\begin{tabular}{lcrrrr}
\hline Ideology & $-6.700^{*}(2.957)$ & $-4.619(3.610)$ & $-7.623^{*}(3.078)$ & $-5.096(3.727)$ \\
Small party & $1.023^{* *}(0.228)$ & $6.633(5.084)$ & $0.998^{* *}(0.228)$ & $8.043(5.230)$ \\
Ideology $\mathrm{x}$ & & $-6.981(6.325)$ & & $-8.771(6.523)$ \\
$\quad$ small party & & & & \\
Coalition & $2.521^{* *}(0.291)$ & $2.560^{* *}(0.290)$ & $2.845^{* *}(0.340)$ & $2.904^{* *}(0.339)$ \\
Candidate & $0.766^{* *}(0.208)$ & $0.766^{* *}(0.207)$ & $0.806^{* *}(0.214)$ & $0.807^{* *}(0.213)$ \\
Time & & & $-0.395^{* *}(0.133)$ & $-0.410^{* * *}(0.134)$ \\
Constant & $2.382(2.382)$ & $0.686(2.927)$ & $3.474(2.487)$ & $1.429(3.023)$ \\
\hline
\end{tabular}

Notes: Entries are results from logit models. Dependent variable: deserting the pre-electoral coalition. $(1=$ desertion; $0=$ loyal). Robust standard errors in parentheses. $\mathrm{N}=987$. * Significant at 0.05 . ** Significant at 0.01 . Analysis is limited to respondents who voted for a cartel party in the party vote condition. 
desert the coalition diminish as they grow more familiar with the PEC. Interestingly, when comparing with the results from model 1 , none of the other effects is reduced, so that model 3 indeed confirms all five of our initial hypotheses. It has to be noted that the precision of the estimated effect of disliking the coalition partner remains higher than the one of the effect of ideological congruence. Finally, when additionally including the interaction effect (model 4), the estimated time effect remains strongly negative while we do not observe any major changes compared to the results of model 2.

The results listed in Table 3 confirm our initial hypotheses across several different specifications. The stronger the ideological congruence between the coalition partners, the less likely respondents are to desert the coalition. Ideological congruence between two coalition parties is not only important for forming a PEC (Golder 2005, 2006), but also for voters at the polls. The Asymmetry Hypothesis is confirmed, as supporters of small coalition parties are less likely to remain loyal to the cartel. The most robust effect, however, seems to be the feeling the respondent has toward the other coalition party (Coalition Likeability Hypothesis). To put it simply: voters do not stay loyal to the cartel if they do not like the coalition partner. The analysis shows that this feeling is not necessarily related to ideological distance. N-VA voters might well feel that the $C D \& V$ is ideologically close to their own preferred party, but they might still dislike the party for other reasons. The theoretically relevant finding here is that the feeling of dislike toward a party is not just related to ideological distance, or left-right placement, but might also be caused by other, cultural, historical or other idiosyncratic elements. The effect of liking candidates from competing parties is clearly weaker, but it is significant: candidates from competing parties can exert strong cross-pressures, and therefore 'seduce' voters into deserting the coalition. The likelihood of deserting the PEC declined during the 2003-2005 observation period. Obviously, it takes a number of years before voters get used to the idea of a PEC, and become more loyal to their party elites.

\section{Estimating the likelihood of desertion}

When party elites enter a pre-electoral coalition they do not always have reliable information on how voters will react to the formation of such a coalition. Although it is likely that they will have gathered some information on the perception of the cartel among their voters (Kaminski 2001,2002), this still does not allow them to predict future voter behaviour in a reliable manner. With this experiment we wanted to find out why voters are more or less likely to follow party elites into a pre-electoral cartel, and to try to 
ascertain on what grounds they take this decision. While our logit models already give part of the answer to these questions, we can also present our findings more intuitively. How much more (or less) likely are supporters of particular parties to follow their party into a coalition? We will answer this question under four different sets of (realistic) conditions derived from our hypotheses, and generate predicted probabilities as well as uncertainty estimates for those scenarios. The scenarios depend on whether voters initially support a small party (first row in Figure 1) or a large party (second row) as well as whether the voter's favourite politician is affiliated with the PEC to

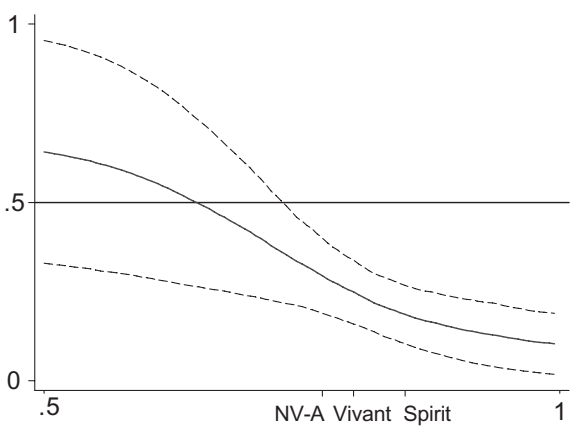

Small party supporter \& favourite candidate affiliated with PEC

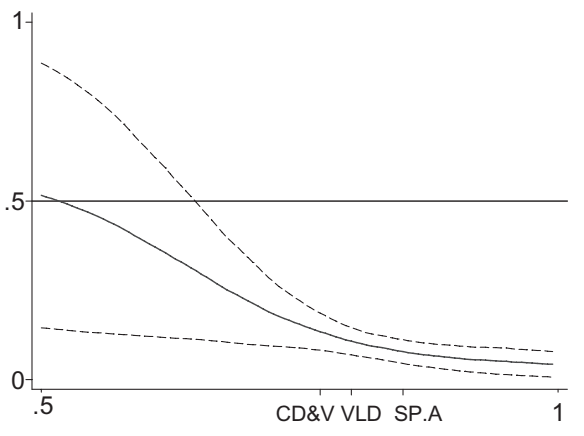

Large party supporter \& favourite candidate affiliated with PEC

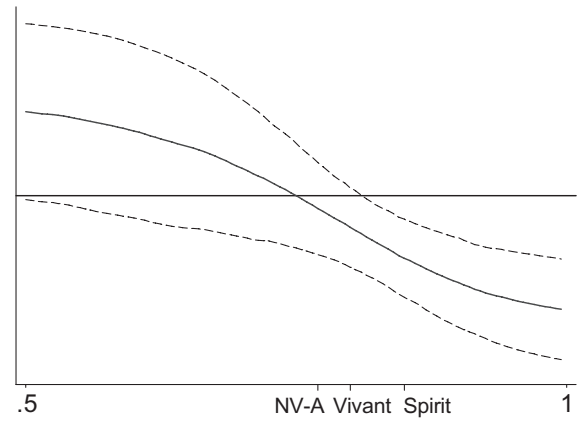

Small party supporter \& favourite candidate not affiliated with PEC

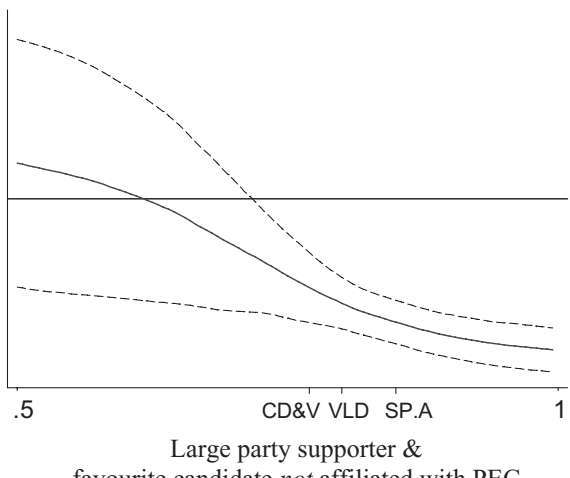
favourite candidate not affiliated with PEC

Ideological Congruence

Figure 1. Predicted probability of deserting the PEC, as a result of ideological congruence and candidate likeability. Straight lines represent the point predictions; dashed lines represent the 95 per cent confidence intervals. Y-axis: Predicted probability of deserting the PEC. $\mathrm{X}$-axis: Degree of ideological congruence between coalition partners. Point predictions and confidence intervals are calculated from the estimated coefficients of model 3 using Clarify (Stata 9) with 'Coalition' set to its sample mean, and 'Time' to 0. 
which the voter's most-preferred party belongs (left column) or not (right column). For those four scenarios we determine how ideologically congruent the respective coalition parties have to be in order to convince voters to remain loyal to the coalition.

In all four graphs in Figure 1, the predicted probability of deserting the PEC is on the y-axes and the degree of ideological congruence between coalition partners is on the $\mathrm{x}$-axes. The solid line depicts the predicted probability that a voter will desert the PEC, given a certain degree of perceived ideological congruence between actual or hypothetical coalition partners. Theoretically we would expect the line to drop from almost ' 1 ' (the voter is almost 100 per cent likely to desert) if there is no ideological congruence, towards ' 0 ' (the voter is 100 per cent likely to remain loyal to the PEC) if ideological congruence would be ' 1 '. For every graph, we also add the 95 per cent confidence intervals (dashed lines) to the panels. ${ }^{12}$

Figure 1 illustrates that the ideological congruence of coalition partners is generally more important for supporters of small coalition partners: if ideological congruence is low (in the figure the minimum value is 0.5 ), they are more likely to desert than voters for large coalition partners. The likelihood that a voter will desert is boosted, both for supporters of small and large parties, as expected, if their favourite candidate is not affiliated to the preelectoral coalition. By looking at the various panels in Figure 1, we can ascertain how likely it is that voters will follow the party elite into a pre-electoral coalition. The predicted form of the curve indicates that ideological congruence is a key element in this decision. Party elites, therefore only can take it for granted that voters will follow their cues if there is a strong ideological congruence between the parties. Voters of smaller coalition parties are generally less loyal, while party elites should also take into account the cross-pressure effects of popular candidates of other party or pre-electoral coalitions.

Instead of looking at the full range of hypothetical ideological congruence scores, we now focus particularly on three measured values of ideological congruence in our data: 0.77 for CD\&V and NV-A; 0.80 for VLD and Vivant; and 0.85 for SP.A and Spirit. Comparing both graphs in the left column shows that across all three coalitions the respective small party supporters (likelihood for desertion: NV-A: 0.28 , Vivant: 0.24 , Spirit: 0.17 ) are in general more than twice as likely to desert the coalition as supporters of their larger coalition partner (CD\&V: 0.12, VLD: 0.10, SP.A: 0.07). Even if the favourite candidate is not affiliated with the PEC, as the graphs in the right column show, supporters of small parties are still about twice as likely to desert the coalition (NV-A: 0.46; Vivant: 0.40; Spirit: 0.31 versus CD\&V: 0.24; VLD: 0.20 and SP.A: 0.14). In each panel, the predicted differences between the parties are statistically different from zero. Generally though, given the actual measured ideological 
congruence scores, the model predicts that voters should rather 'stay' and follow the lead of their party elites than 'go' and desert the coalition at the polls. Based on the predicted probabilities of our chosen scenarios, only supporters of NV-A or Vivant might potentially desert the coalition (the respective confidence intervals include the 0.5 reference line in the upper right panel) when also favouring a candidate who is not affiliated with the coalition.

To summarise, party elites can in fact reasonably expect that voters will follow their lead and cast a vote for a PEC as long as the coalition parties are not too different ideologically. Supporters of smaller coalition partners typically find it harder 'to stay' loyal and vote for the PEC than supporters of the larger coalition parties, particularly if other popular candidates exist who cross-pressure the voters' decision-making processes. The practical relevance of these findings is that when negotiating a PEC, party elites have every reason to be responsive to the wishes of the small coalition party's supporters because they are the first who desert the PEC. We suggest that henceforth party elites coordinating policy proposals as well as the recruitment of political personnel before an election should be especially attentive to the preferences of the small coalition party supporters. Given that parties are able to make an agreement on common policies, the most important point for the PEC to be successful at the polls is that the election campaign of the PEC should focus particularly on those politicians who are (potentially) popular with supporters of the small coalition partner. This way the votes of small party supporters are secured. Moreover, negotiating policy agreements that maximise ideological congruence between coalition partners is hard to do, particularly under time pressure in a competitive environment before an election. Therefore focusing the campaign on politicians who are popular with small party supporters of a given PEC allows party elites to trade this campaign strategy for harder-toreach policy agreements that would send their small party supporters a stronger signal of policy congruence. A unique feature of this round of experiments is that we started just after the formation of PECs in Belgium and could repeat it in two consecutive years. Comparing the three waves of the experiment confirms the existence of an adjustment effect, implying that loyalty toward the cartel increases over the years.

\section{Discussion}

Thus far, the success of pre-electoral coalitions has only been studied on the macro-level, as Golder $(2005,2006)$ has demonstrated under what conditions party elites are more likely to enter such a coalition. This experiment allows us, for the first time, to assess voters' reactions to the formation of pre-electoral 
cartels, and in this regard a number of findings stand out. First, we find strong effects, both of ideological congruence and of dislike of the coalition partner. While the first effect could be expected, the strength of the second effect comes as a bit of a surprise. It shows that dislike toward the coalition partner cannot be explained completely by ideological congruence. The past of the party, its image and its previous experience with power seem to have an additional effect on the assessment of its likeability. What exactly determines disliking a party, however, remains to be investigated. Second, we observe a distinct difference with regard to the loyalty of supporters of the larger coalition partner compared to those associated with the junior partner. A possible explanation for this pattern could be that supporters of the senior coalition partner are less concerned with whom 'their' party associates itself since they assume that their party will dominate the coalition anyhow. For the supporters of the junior party, on the other hand, this is something that cannot be taken for granted.

Our experimental research design allows us to reconstruct to some extent the mental map voters have of the party system. What is perhaps counterintuitive is that there are many voters who would not consider voting for either coalition partner, but who are attracted to the coalition as a whole: every coalition attracts at least some voters who did not vote for either of the two constituent parties. Thus the experiment offers us a glimpse of the mental processes voters might experience when they determine whether or not to vote for a party, or a coalition. While a lot of research has been conducted on the question of why some voters prefer a specific party, maybe the question might as well be how voters construct a relative ranking of parties. This would imply that if a party gains in attractiveness - for example, by joining a coalition - this also has an effect on the ranking of parties that are not include in the coalition (Kabashima \& Reed 2001). An alternative explanation might be that such a ranking for some voters simply is not important, while the issue becomes more salient for them once PECs have been brought together.

Party elites often do not have any information on what the reaction of voters will be when they decide to enter a pre-electoral coalition. ${ }^{13}$ The Belgian case imposes limits to our capacity to research this asymmetrical effect further. All three PECs in Belgium were formed between a large party and a clearly much smaller party. Therefore we cannot ascertain whether the absolute or rather the relative size of the party is important. If the absolute size is important, this would imply that voters for (very) small parties pay more attention to expressive concerns like ideology and ideological congruence, and that they are less interested in instrumental motivations of power, representation in parliament and government and so on. The further implication could be that voting for a small party is more of an expressive act than voting for a large 
party. If the relative size is important, on the other hand, this would imply that our findings are not caused by size as such, but by the fact that in these cases there clearly was a senior and a junior coalition partner. To ascertain whether the asymmetrical effect is based on absolute or relative size, we would need a research setting where PECs have been formed between parties of relatively equal strength, whether they are small or large. What we hope to have demonstrated in this article, however, is that in this kind of setting too, our research design can be applied successfully.

\section{Acknowledgements}

An earlier version of this article was presented at the Fourth Dutch-Belgian Political Science Conference, Antwerp, 19-20 May 2005. We would like to thank the participants at this conference for their constructive comments. Both authors contributed equally to this article.

\section{Notes}

1. In principle, this web-based experiment could also be used in a representative sample of the population. Participation in web-based surveys, however, usually is heavily biased (Sparrow \& Curtice 2004). It could also be argued that because of cognitive sophistication, our student sample is not ideal for an experiment like this. It has to be remembered, however, that the experiment was conducted during the first weeks the students were enrolled at the university, while it is also useful to know that Belgian universities do not have an entrance examination, resulting in a broader recruitment pattern compared to universities in other countries.

2. Theoretically voters could also just stay at home. Given that our study is placed in Belgium, a country with a system of compulsory voting, this is not an issue.

3. Since the 1980s, Belgium no longer has national parties. There is a Dutch-speaking party system, and a French-speaking party system, and parties do not compete across the country. This experiment is limited to the Dutch-speaking party system since the electoral threshold had clear effects only among the Flemish parties, and it was only in the Flemish part of the country that electoral coalitions were formed. In the Frenchspeaking part of the country, little changed in the party system.

4. The Belgian cartels are just one of the possible pre-electoral coordination strategies that are available to party elites. Since we wanted to reflect Belgian political reality, we did not test other coordination mechanisms in our experiment. As such, our findings are limited to the reactions to this specific form of pre-electoral cartels and they should not be generalised to all other forms of pre-electoral coordination.

5. It has to be noted that the simultaneous formation of other cartels might also have an effect on the voting decision. Moreover, because of the 2003 electoral reform, all the cartels were formed rather simultaneously in Belgian politics. The experiment thus 
reflects real-life conditions most accurately. Also, increasing the number of scenarios would have led to the formation of groups that are too small to be interpreted meaningfully.

6. As can be noticed, the Vlaams Blok only obtained 2.9 per cent of the vote, which is far below its actual score in Flanders of 24 per cent. Partly this is a result of the specific student sample, but we can also assume that some students clearly did not want to reveal their preference for the party. This kind of under-representation of the extreme-right is quite common in election research in Flanders (Billiet 1995).

7. Moreover, it is comforting to see that being exposed to both conditions does not make a difference for supporters of non-coalition parties. Looking at the supporters of the non-coalition parties (Groen!, Vlaams Blok and the 'Others'), they essentially report the same vote intention providing validity to our experimental manipulations of the difference between the choice-sets in both conditions.

8. We would like to thank Jaak Billiet (Leuven), Wouter Teepe (Groningen) and Kris Deschouwer (Brussels) for their help in assembling these data.

9. The results stay qualitatively the same if we use either of those ideology measures. For methodological reasons, therefore, we opted for using the double measurement.

10. The list consisted of the following candidates: Bart Somers and Karel De Gucht (VLD); Steve Stevaert, Freya van den Bossche and Patrick Janssens (SP); Yves Leterme, JeanLuc Dehaene and Stefaan De Clerck (CD\&V); Bert Anciaux (Spirit); Philippe Dewinter (Vlaams Blok); Geert Bourgeois (NVA); and Vera Dua (Agalev).

11. Self-evidently, these were different groups of students, except perhaps for a very limited number of unsuccessful students that took the same introductory course twice.

12. All point predictions are calculated from the model formula straightforwardly, using the estimated coefficients from Table 3 (model 3 ) and the values of the independent variable that define these scenarios. We, therefore, set 'Coalition' to its sample mean (0.15) and 'Time' to zero. Confidence intervals for those point predictions are calculated using the method of statistical simulations (King et al. 2000) as employed in the 'clarify-suite' in Stata 9. We took 1,000 random draws from the multivariate normal distribution with the vector of estimated coefficients from Table 3 as the mean and the estimated variancecovariance matrix as variance.

13. Apparently in Poland, some parties hired polling companies in order to find out whether forming a PEC might actually benefit them (Kaminski 2001: 302, Note 4).

\section{References}

Andrews, J. \& Jackman, R. (2005). Strategic fools: Electoral rule choice under extreme uncertainty. Electoral Studies 24(1): 65-84.

Billiet, J. (1995). Church involvement, Ethnocentrism and voting for a radical right-wing party. Sociology of Religion 56(3): 303-326.

Boix, C. (1999). Setting the rules of the game: The choice of electoral systems in advanced democracies. American Political Science Review 93: 609-624.

Cox, G. (1997). Making votes count: Strategic coordination in the world's electoral systems. Cambridge: Cambridge University Press.

Deschouwer, K. \& Nuytemans, M. (2005). De stemtest van de VRT: een kijk in de keuken. Samenleving en Politiek 12 (special issue): 13-31.

Downs, A. (1957). An economic theory of democracy. New York: Harper \& Row. 
Ferrara, F. \& Herron, E. (2005). Going it alone? Strategic entry under mixed electoral rules. American Journal of Political Science 49(1): 16-31.

Fiske, S. \& Taylor, S. (1991). Social cognition. New York: McGraw-Hill.

Golder, S.N. (2005). Pre-electoral coalitions in comparative perspective: A test of existing hypotheses. Electoral Studies 24(4): 643-664.

Golder, S.N. (2006). Pre-electoral coalition formation in parliamentary democracies. British Journal of Political Science 36(2): 193-212.

Gschwend, T. \& Leuffen, D. (2005). Divided we stand - Unified we govern? The issue of cohabitation in the French elections of 2002. British Journal of Political Science 35(4): 691-712.

Hooghe, M., Noppe, J. \& Maddens, B. (2003). The effect of electoral reform on the Belgian election results of 18 May 2003. Representation 39(4): 270-276.

Hooghe, M., Maddens, B. \& Noppe, J. (2006a). Why parties adapt: Electoral reform, party finance and party strategy in Belgium. Electoral Studies 25(2): 351-368.

Hooghe, M., Vermaut, A. \& Libbrecht, L. (2006b). Verkiezingen eerste kandidatuur/eerste bachelor (dataset). Leuven: Department of Political Science, Catholic University of Leuven.

Kabashima, I. \& Reed, S. (2000). Voter reactions to 'strange bedfellows': The Japanese voter faces a kaleidoscope of changing coalitions. Japanese Journal of Political Science 1(2): 229-248.

Kabashima, I. \& Reed, S. (2001). The effect of the choices available on voting behaviour: The two Japanese elections of 1993. Electoral Studies 20(4): 627-640.

Kaminski, M. (2001). Coalition stability of multi-party systems: Evidence from Poland. American Journal of Political Science 45(2): 294-312.

Kaminski, M. (2002). Do parties benefit from electoral manipulation? Electoral laws and heresthetics in Poland, 1989-1993. Journal of Theoretical Politics 14(3): 325-358.

King, G., Tomz, M. \& Wittenberg, J. (2000). Making the most of statistical analyses: Improving interpretation and presentation. American Journal of Political Science 44(2):347-361.

Lavine, H. \& Gschwend, T. (2007). Issues, parties and character: The moderating role of ideological thinking on candidate evaluation. British Journal of Political Science 37(1): 139-163.

Martin, L. \& Vanberg, G. (2003). Wasting time? The impact of ideology and size on delay in coalition formation. British Journal of Political Science 33(2): 323-332.

Popkin, S. (1991). The reasoning voter. Chicago, IL: University of Chicago Press.

Powell, G.B. (2000). Elections as instruments of democracy: Majoritarian and proportional visions. New Haven, CT: Yale University Press.

Sparrow, N. \& Curtice, J. (2004). Measuring the attitudes of the general public via Internet polls: An evaluation. International Journal of Market Research 46(1): 23-44.

Wattenberg, M. (1991). The rise of candidate-centered politics. Cambridge, MA: Harvard University Press.

Correspondence to: Marc Hooghe, Department of Political Science, Catholic University of Leuven, E van Evenstraat 2B, Leuven, B-3000 Belgium. Email: Marc.Hooghe@ soc.kuleuven.be 